\title{
Gastroretentive drug delivery system of a lipid lowering agent
}

\author{
${ }^{*}$ D. Krishnarajan ${ }^{1}$, N. Senthil Kumar², Rajesh Yadav ${ }^{3}$ \\ ${ }^{1}$ Department of Pharmaceutics, JKK Munirajah Medical Research Foundation College of Pharmacy, Ethirmedu, B.Komarapalaym, \\ Namakkal-638183, Tamilnadu, India \\ ${ }^{2}$ Department of Pharmaceutical Chemistry, JKK Munirajah Medical Research Foundation College of Pharmacy, Ethirmedu, \\ B.Komarapalaym, Namakkal-638183, Tamilnadu, India \\ ${ }^{3}$ Department of Pharmacy, Sunrise Univercity, Alwar, Rajasthan-301030, India
}

\begin{abstract}
The objective of this study was to develop mucoadhesive tablets of Simvastatin using natural polymers. Simvastatin has short biological half-life and high first pass metabolism hence which was designed to increase the gastric residence time which prolong the drug release. The tablets were prepared by wet granulation technique using Carbopol-934, guar gum, xanthine gum and chitosin as polymers. Formulations were evaluated for different parameters like hardness, friability, uniformity of weight, swelling char acteristics, in vitro dissolution and kinetic studies. The dissolution was carried out for 12 hours in which the formulation with guar gum has shown highest dissolution release profile (F9). Thus the present study concludes that mucoadhesive tablets of simvastatin can be a good way to pass the extensive hepatic first pass metabolism and to improve the bioavailability of simvastatin.
\end{abstract}

Key Words: Simvastatin, Mucoadhesive, Carbopal-934, Gastric residence time, swelling characters.

\section{INTRODUCTION}

In recent years, there has been increasing interest on the use of bioadhesive polymers. Per oral drug delivery has been the most widely utilized route of administration for the systemic delivery of drugs. The lack of efficacy of certain drugs due to decreased bioavailability, unpredictable and erratic absorption, GI intolerance or pre-systemic elimination has prompted the examination of other potential routes for administration. Moreover, the recent development of a large number of peptides as drugs has intensified investigation of mucosal delivery of drugs (Vinod et al., 2012). Such routes exploring other absorptive mucosa include the oral, nasal, buccal, rectal, vaginal and ocular to a limited extend, pulmonary routes amongst the various route of drug delivery, oral route is perhaps the most preferred to the patient and the clinician alike. However, per oral administration of drugs has disadvantages such as hepatic first pass metabolism and enzymatic degradation within the GIT, that prohibit oral administration of certain classes of drugs especially peptides and proteins. Consequently, other absorptive mucosa is considered as potential sites for drug administration (Vyas and Khar, 2002).

Simvastatin is HMG Co-A (3-hydroxy-3-methylglutaryl-CoA) reductase inhibitors widely used in the treatment of hyper cholesterolemia, as it reduces levels of low-density lipoproteins and triglycerides, and raises high-density lipoprotein levels. Simvastatin undergoes extensive first pass metabolism in liver due to which the oral bioavailability is less dose size i.e., in few mg. Hence, it is suitable candidate for mucoadhesive drug delivery (Goud et al., 2011).

In this study, the main objective is to develop and evaluate mucoadhesive tablets of Simvastatin by employ-

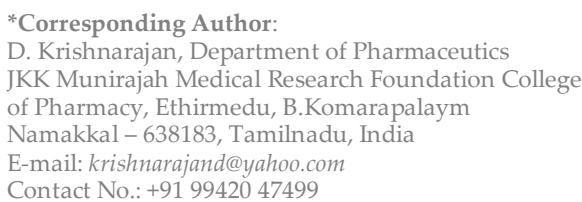

ing various natural hydrophilic bioadhesive polymers such as xanthan gum, chitosin, guar gum and carbopol for prolonged gastrointestinal absorption. The prepared tablets were evaluated for different parameters such as hardness, friability, weight variation, swelling index, invitro residence time and ex-vivo adhesive time.

\section{MATERIALS AND METHODS}

Simvastatin was collected as a gift sample from Aurobindo Pharma Ltd., Hyderabad, polymers were purchased from Yarrow Chem Products, Mumbai and all remaining excipients were purchased from Scientific Lab, Erode.

\section{IR studies of Simvastatin with natural polymers} Infrared spectra analysis

Compatibility of the drug with the excipients was determined by subjecting the physical mixture of the drug and polymer of the main formulation to infrared spectral analysis. Any changes in chemical composition of the drug after the combining it with the polymers were investigated with IR spectral analysis (Harry, 2006). Infrared spectrum of simvastatin was determined on Fourier transform infrared spectrophotometer using $\mathrm{KBr}$ pellet method. The base line correction was done using dried potassium bromide. Then the spectrum of the dried mixture of the drug and potassium bromide was done.

\section{Preparation of the bio-adhesive tablet}

Simvastatin bioadhesive oral tablets were prepared by the wet granulation method. In all the formulations, amount of the active ingredient was $20 \mathrm{mg}$. All the ingredients of the tablet were granulated to obtain uniform mixing. All the tablets were stored in airtight containers at room temperature for further study (Deshmukh et al., 2009).

\section{Evaluation of the bio-adhesive tablets Uniformity of weight}

The weight variation test was done by taking 20 tablets randomly and weighed accurately. The composite weight divided by 20 provides an average weight of tablet. Not more than two of the individual weight deviates from the 
Table 1: Composition of simvastatin mucoadhesive tablets.

\begin{tabular}{|c|c|c|c|c|c|c|c|}
\hline \multirow[b]{2}{*}{$\begin{array}{c}\text { Batch } \\
\text { number }\end{array}$} & \multicolumn{7}{|c|}{ Amount of ingredients (in mg) } \\
\hline & 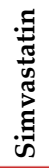 & 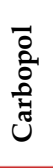 & 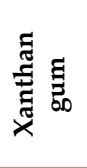 & 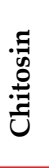 & 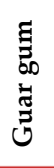 & 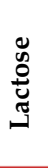 & 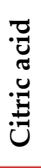 \\
\hline F1 & 20 & 20 & 20 & - & - & 40 & 10 \\
\hline $\mathrm{F} 2$ & 20 & 20 & 40 & - & - & 20 & 10 \\
\hline F3 & 20 & 20 & 60 & - & - & & 10 \\
\hline $\mathrm{F} 4$ & 20 & 20 & - & 20 & & 40 & 10 \\
\hline F5 & 20 & 20 & - & 40 & & 20 & 10 \\
\hline F6 & 20 & 20 & - & 60 & & - & 10 \\
\hline F7 & 20 & 20 & - & - & 20 & 40 & 10 \\
\hline F8 & 20 & 20 & - & - & 40 & 20 & 10 \\
\hline F9 & 20 & 20 & - & - & 60 & - & 10 \\
\hline F10 & 20 & 20 & 30 & 30 & - & 20 & 10 \\
\hline F11 & 20 & 20 & - & 30 & 30 & 20 & 10 \\
\hline F12 & 20 & 20 & 30 & - & 30 & 20 & 10 \\
\hline
\end{tabular}

average weight by $10 \%$ and none should deviate by more than twice that percentage. The average weight and standard deviation of the tablets were calculated.

\section{Hardness test}

There is a certain requirement of hardness in tablets so as to withstand the mechanical shocks during handling, manufacturing, packaging and shipping. For each formulation, the hardness of 6 tablets was determined using the Monsanto hardness tester. Monsanto hardness tester was used to measure hardness of the tablets. The whole experiment was performed in triplicate and the results are expressed in $\mathrm{kg} / \mathrm{cm}^{2}$ unit.

\section{Friability test}

Friability is the measure of tablet strength. This test subjects a number of tablets to the combined effect of shock abrasion by utilizing a plastic chamber which revolves at a speed of $25 \mathrm{rpm}$ for 4 minutes, dropping the tablets to a distance of 6 inches in each revolution. A sample of pre-weighed tablets was placed in Roche friabilator which was then operated for 100 revolutions. The tablets were then dedusted and reweighed. Generally considered and acceptable limit is loss of less than $1 \%$ in weight. Percent friability $(\% F)$ was calculated.

\section{In-vitro swelling study (water uptake study)}

The tablets of each formulation were weighed individually (designated as $\mathrm{W}_{1}$ ) and placed separately in petri dishes containing $2 \%$ agar gel. At regular intervals $(1,2,3,4,5,6$, 7 and $8 \mathrm{hr}$ ), the tablets were removed from the petri dishes and excess water was removed carefully by using filter paper (Ramana et al., 2007). The swollen tablets were reweighed $\left(\mathrm{W}_{2}\right)$, the swelling index of each formulation was calculated using the formula

$\%$ Swelling Index $=\frac{\mathrm{w} 2-\mathrm{w} 1}{\mathrm{w} 1} \times 100$

Where, $\mathrm{W}_{2}$ - weight of tablet after particular time interval $\mathrm{W}_{1}$ - initial weight of tablet

\section{Evaluation of bio-adhesive strength of tablet}

Measurement of adhesion force was determined by using goat gastric mucus membrane. The tissues were washed thoroughly with phosphate buffer solution ( $\mathrm{pH}$ 6.8) then the membrane was tied to the glass slide using rubber band. The glass slide was kept in a beaker which was filled with phosphate buffer solution at $37 \pm 1^{\circ} \mathrm{C}$ in such way that buffer just reaches the surface of mucosal membrane and kept it moist. The tablet to be tested was stuck on the mucus membrane and allow for $5 \mathrm{~min}$ for swelling and then by using clip to attach the tablet. Then the weight on the left hand side was slowly added in an increment of $0.5 \mathrm{~g}$ till the tablet separated from the membrane (Gupta et al., 1993). From bio-adhesive strength, the force of adhesion was calculated using the formula.

Force of adhesion $(N)=\frac{\text { Mucoadhesive strength }}{100} \times 9.81$

\section{Ex-vivo mucoadhesion time}

The ex-vivo mucoadhesion time was examined after application of tablet over excised goat mucosa for 30sec after previously being secured on glass slab and was immersed in a basket of the dissolution apparatus containing around $750 \mathrm{ml}$ of phosphate buffer, $\mathrm{pH} 6.8$ at $37 \pm 1^{\circ} \mathrm{C}$. The paddle of the dissolution apparatus was adjusted at a distance of $5 \mathrm{~cm}$ from the tablet and rotated at $25 \mathrm{rpm}$. The time for detachment from the mucosa was recorded (Chowdary, 2008).

\section{In-vitro drug release studies}

The dissolution test apparatus (USP II) was used and the whole assembly was kept in a jacketed vessel of water maintained at $37 \pm 1^{\circ} \mathrm{C}$. Bio adhesive tablet was stuck on to the bottom of the flask (so as to allow one sided release from the tablet). The beaker was filled with $900 \mathrm{ml}$ of phosphate buffer and was maintained at 50rpm under stirring conditions by means of a paddle fabricated for the purpose in a dissolution apparatus. At various time intervals samples of dissolution medium were withdrawn and filtered through Whatman filter paper no: 42. It was replaced immediately with an equal amount of fresh buffer. The samples were then analyzed UV spectrophotometrically at $238 \mathrm{~nm}$. Absorbance measured and \% drug release was determined (Balamurugan et al., 2008).

\section{Stability studies}

The selected F9 formulation was packed in PVC blister pack then they were stored at three different temperatures $4 \pm 2^{\circ} \mathrm{C}, 27 \pm 2^{\circ} \mathrm{C}$ and $45 \pm 2^{\circ} \mathrm{C}$ for 30 days at $\mathrm{RH} 75 \pm 5 \%$. At 15 days interval, the tablets were evaluated for their physical appearance, hardness, friability, in-vitro drug release (Matthews, 1999).

\section{Drug release kinetics}

To study the release kinetics of in-vitro drug release, data was applied to kinetic models such as zero order, first order, Higuchi and Korsmeyer- Peppas.

\section{Zero order}

Drug dissolution from dosage forms that do not disaggregate and release the drug slowly can be represented by the equation:

$\mathrm{C}=\mathrm{k}_{0} \mathrm{t}$

$\mathrm{K}_{0}$ - is the zero order release constant

To study the release kinetics, data obtained from in vitro drug release studies were plotted as cumulative amount of drug released versus time.

First order

This model has also been used to describe absorption and/or elimination of some drugs, although it is difficult to conceptualize this mechanism on a theoretical basis. 
Table 2: Physical parameter of simvastatin mucoadhesive tablet.

\begin{tabular}{|c|c|c|c|c|}
\hline 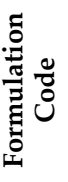 & 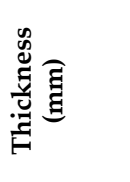 & 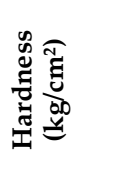 & 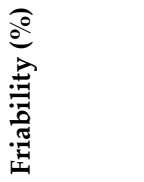 & 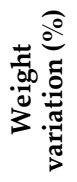 \\
\hline F1 & $2.66 \pm 0.10$ & $1.8 \pm 0.25$ & $0.01 \pm 0.03$ & 0.118 \\
\hline F2 & $2.54 \pm 0.12$ & $1.81 \pm 0.25$ & $0.03 \pm 0.07$ & 0.119 \\
\hline F3 & $2.01 \pm 0.15$ & $1.79 \pm 0.27$ & $0.032 \pm 0.08$ & 0.12 \\
\hline $\mathrm{F} 4$ & $2.61 \pm 0.07$ & $1.7 \pm 0.20$ & $0.002 \pm 0.07$ & 0.121 \\
\hline F5 & $2.97 \pm 0.08$ & $1.9 \pm 0.27$ & $0.012 \pm 0.01$ & 0.119 \\
\hline F6 & $2.86 \pm 0.14$ & $1.75 \pm 0.25$ & $0.011 \pm 0.04$ & 0.12 \\
\hline F7 & $3.03 \pm 0.07$ & $1.2 \pm 0.20$ & $0.23 \pm 0.04$ & 0.122 \\
\hline F8 & $3.11 \pm 0.08$ & $1.41 \pm 0.19$ & $0.31 \pm 0.02$ & 0.118 \\
\hline F9 & $3.07 \pm 0.08$ & $1.49 \pm 0.27$ & $0.36 \pm 0.02$ & 0.12 \\
\hline F10 & $2.86 \pm 0.12$ & $1.71 \pm 0.20$ & $0.21 \pm 0.04$ & 0.119 \\
\hline F11 & $3.01 \pm 0.13$ & $1.8 \pm 0.12$ & $0.24 \pm 0.02$ & 0.118 \\
\hline F12 & $2.98 \pm 0.11$ & $1.76 \pm 0.17$ & $0.04 \pm 0.02$ & 0.121 \\
\hline
\end{tabular}

The release of the drug which followed first order kinetics can be expressed by the equation

$\log C=\log C_{0} n K t / 2.303$

where,

$\mathrm{C}_{0}$ - is the initial concentration of drug

$K$ - is the first order constant

$t$ - is the time in hrs.

The data obtained were plotted as log cumulative percentage of drug remaining vs. time which would yield a straight line with a slope of $-\mathrm{K} / 2.303$.

Higuchi

It describes the release of drugs from insoluble matrix as a square root of time dependent process based on Fickian diffusion.

$\mathrm{Q}=\mathrm{Kt}_{2}^{1}$

Where, $\mathrm{K}$ is the constant reflecting the design variables of the system. Hence drug release rate is proportional to the reciprocal of the square rot time (Biswas et al., 2008).

Korsmeyer Peppas

It derived a simple relationship which described drug release from a polymeric system equation. To find out the mechanism of drug release, first $60 \%$ drug release data were fitted in Korsmeyer-Peppas model.

$\frac{M_{t}}{M_{\infty}}=$ K. $\mathrm{t}^{\mathrm{n}}$

Where, $\mathrm{Mt} / \mathrm{M} \infty$ - is a fraction of drug released at time $\mathrm{t}, \mathrm{k}$ is the release rate constant and $\mathrm{n}$ is the release exponent.
Table 3: Mucoadhesion study data.

\begin{tabular}{ccccc}
\hline $\begin{array}{c}\text { Batch } \\
\text { no. }\end{array}$ & $\begin{array}{c}\text { Muco- } \\
\text { adhesive } \\
\text { strength }(\text { gm) }\end{array}$ & $\begin{array}{c}\text { Muco- } \\
\text { adhesion } \\
\text { force }\end{array}$ & $\begin{array}{c}\text { In vitro } \\
\text { residence } \\
\text { time }\end{array}$ & $\begin{array}{c}\text { Ex vivo } \\
\text { mucoadhesion } \\
\text { time }\end{array}$ \\
\hline F1 & 20.41 & 2.133 & $>3$ hours & $>6$ hours \\
F2 & 20.50 & 1.966 & $>3$ hours & $>6$ hours \\
F3 & 20.90 & 1.814 & $>3$ hours & $>6$ hours \\
F4 & 18.5 & 1.814 & 1 hours & 2 hours \\
F5 & 18 & 1.765 & 1 hours & 2 hours \\
F6 & 17.15 & 1.711 & 1 hours & 2 hours \\
F7 & 20.05 & 1.966 & $>3$ hours & $>6$ hours \\
F8 & 19.50 & 1.912 & $>3$ hours & $>6$ hours \\
F9 & 21.75 & 2 & $>3$ hours & $>6$ hours \\
F10 & 18.5 & 1.814 & 2 hours & 3 hours \\
F11 & 18.25 & 1.79 & 2 hours & 3 hours \\
F12 & 20.5 & 1.966 & $>3$ hours & $>6$ hours \\
\hline
\end{tabular}

\section{RESULTS AND DISCUSSION}

All the formulations were evaluated for physical properties and hardness of the tablet in the range of $1-2 \mathrm{~kg} / \mathrm{cm}^{2}$. Percentage weight loss in the friability test was less than $0.4 \%$ in all the formulation batches. Thicknesses of all the formulation was less than $3.5 \mathrm{~mm}$. Overall, the prepared tablet batches were of good quality with regard to hardness, friability, and thickness.

Bio-adhesive strength

All the formulation showed good mucoadhesion. The invitro bioadhesive strength study was performed on the modified physical balance to measure the force $(\mathrm{N})$ required for detaching the tablet. The bioadhesion characteristics were affected by the type and concentration of the bioadhesive polymers. Viscosity of the polymer also affected the bioadhesive strength of the tablet. Chitosin batch (F4, F5, F6) showed very low bioadhesive strength, xanthan gum (F1, F2, F3) showed good mucoadhesion and guar gum (F7, F8, F9) showed highest adhesive strength.

\section{Ex-vivo mucoadhesion time}

Ex-Vivo Mucoadhesion time of all formulation (F1-F12) calculated by modified dissolution apparatus. In all the formulation Ex-vivo mucoadhesive time increased more than $6 \mathrm{hrs}$ except formulations F4, F5, F6, F10, F11 it was decreased because of chitosin which displayed a much lower hydration capacity and a higher rate of erosion.

Swelling index

Batch F1-F3 showed 700\% swelling in 8 hrs, batch F4-F6

Table 4: In vitro drug release data.

\begin{tabular}{|c|c|c|c|c|c|c|}
\hline \multirow{2}{*}{ Batch no. } & \multicolumn{6}{|c|}{ Percent release of simvastatin from different test batches } \\
\hline & 1 hour & 2hour & 4 hour & 8 hour & 10 hour & 12 hour \\
\hline F1 & $19 \%$ & $24.3 \%$ & $48.4 \%$ & $78.2 \%$ & $93.11 \%$ & - \\
\hline $\mathrm{F} 2$ & $16.3 \%$ & $21.5 \%$ & $45.9 \%$ & $75.5 \%$ & $82.2 \%$ & $93.36 \%$ \\
\hline F3 & $12.7 \%$ & $19.7 \%$ & $40.21 \%$ & $70.87 \%$ & $81.98 \%$ & $94.7 \%$ \\
\hline $\mathrm{F} 4$ & $22.1 \%$ & $29.8 \%$ & $58.8 \%$ & $97.6 \%$ & - & - \\
\hline F5 & $18.4 \%$ & $27 \%$ & $55.5 \%$ & $89.5 \%$ & $94.2 \%$ & - \\
\hline F6 & $16 \%$ & $26.23 \%$ & $52.23 \%$ & $86.05 \%$ & $96.49 \%$ & - \\
\hline F7 & $17.9 \%$ & $23 \%$ & $35.07 \%$ & $67.34 \%$ & $84.62 \%$ & $93.4 \%$ \\
\hline F8 & $14 \%$ & $21.05 \%$ & $32.1 \%$ & $66.5 \%$ & $81.76 \%$ & 95.38 \\
\hline F9 & $12.02 \%$ & $19.2 \%$ & $30.9 \%$ & $64.78 \%$ & $87.34 \%$ & $97.98 \%$ \\
\hline F10 & $21 \%$ & $29 \%$ & $48 \%$ & $85.62 \%$ & $91.32 \%$ & - \\
\hline F11 & $20.4 \%$ & $28.4 \%$ & $46.11 \%$ & $88.68 \%$ & $94 \%$ & - \\
\hline F12 & $13.4 \%$ & $20.32 \%$ & $38 \%$ & $69.23 \%$ & $84.1 \%$ & $94.22 \%$ \\
\hline
\end{tabular}




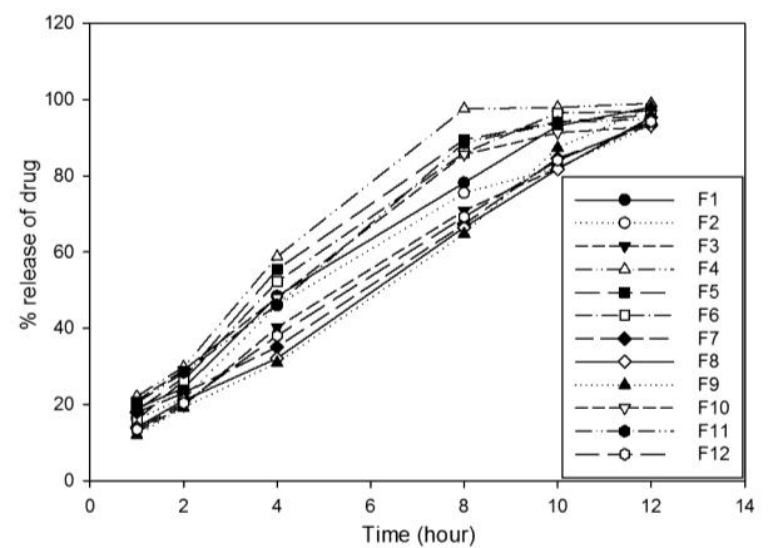

Figure 1: Graph showing in vitro drug release profiles.

showed good swelling (more than 800\%); F7-F9 batch swelling index was $400 \%$ on $8 \mathrm{hr}$.

\section{In-vitro drug release}

From the overall dissolution profiles, it was concluded that the drug release rate decreased as the concentration of the polymer increased, in batch (F1-F6) which was also affected by the type of polymer used. And batch (F7-F9) guar gum with high concentration act as disintegrant and showed extended drug release which is the best in all the formulations.

\section{Drug release kinetics}

The straight line of linear regression analysis indicates zero order of the data yields the equation of best line with $\mathrm{R}^{2}$ value 0.994 and the slope of line corresponds to the zero order rate constant was 8.33. The best linearity was found in zero order equation plot $\left(R^{2}=0.994\right)$ indicating the release from system where release rate is concentration dependent.

According to Korsmeyer, where $\mathrm{n}$ is the release exponent, indicative of mechanism of drug release. Fickian diffusional release and a case-II relaxation release are the limits of this phenomenon. Fickian diffusional release occurs by the usual molecular diffusion of the drug due to a chemical potential gradient. Case-II relaxation release is the drug transport mechanism associated with stresses and state transition in hydrophilic glassy polymers which swell in water or biological fluids. This term also includes polymer disentanglement and erosion. The value of the release exponent in Simvastatin extended release was obtained as 0.588 which follows Anomalous transport $(0.45<\mathrm{n}<0.89)$.

\section{Stability study}

According to $\mathrm{ICH}$ guidelines, 30 days stability study at $4 \pm 2^{\circ} \mathrm{C}, 27 \pm 2^{\circ} \mathrm{C}$ and $45 \pm 2^{\circ} \mathrm{C}$ for 30 days at $\mathrm{RH} 75 \pm 5 \%$ of optimized formulation (F9) was carried out. It showed negligible change over time for parameters like appearance, drug content, dissolution and assay etc., No significant difference in the drug content between initial and formulations stored at $4 \pm 2^{\circ} \mathrm{C}, 27 \pm 2^{\circ} \mathrm{C}$ and $45 \pm 2^{\circ} \mathrm{C}$ for 45 days at $\mathrm{RH} 75 \pm 5 \%$ for 30 days.
Table 5: Stability study data for optimized batch (F9).

\begin{tabular}{cll}
\hline S1. no. & Parameters & Observations \\
\hline 1 & Physical appearance & No change \\
2 & Weight variation & $0.115 \mathrm{~g}$ \\
3 & Hardness & $1-2 \mathrm{~kg} / \mathrm{cm}^{2}$ \\
4 & Friability & $0.342 \%$ \\
5 & In-vitro drug release & $96.27 \%$ \\
6 & Mucoadhesive strength & $21.32 \mathrm{~g}$ \\
\hline
\end{tabular}

\section{CONCLUSION}

Literature review indicates that gastroretentive drug delivery systems can be used to increase the gastric residence time of dosage form, which led to an increased bioavailability of various drugs. Thus, in the present investigation, an attempt was made to deliver simvastatin via an oral bio-adhesive drug delivery system to the vicinity of the absorption site by prolonging the gastric residence time of the dosage form. For the formulation of the oral bioadhesive tablet, various hydrophilic polymers and their combinations were used in varying concentrations.

Tablets were subject to various evaluation parameters such as hardness, friability and drug content, bioadhesive strength study and in-vitro drug release study. It was revealed that tablets of all batches had acceptable physical parameters. Tablets of batch F9 have good mucoadhesion along with in-vitro drug release and thus were selected as an optimized batch. The present study shows that the hydrophilic gums obtained from natural sources can be used for designing a bio-adhesive controlled release drug delivery system.

\section{ACKNOWLEDGEMENT}

Authors are sincerely thankful to the management of JKKMMRF's College of Pharmacy, Kommarapalem, Namakal dist., Tamilnadu for providing the needful facilities and moral support to carry out this research work.

\section{REFERENCES}

Balamurugan M, Saravanan VS, Ganesh P, Senthil SP, Hemalatha PV and Sudhir Pandya. (2008) Development and In-vitro evaluation of mucoadhesive buccal tablets of domperidone research j. pharm. and tech.; 1(4).

Biswas, B.K., Md. Safiqul Islam, Farida Begum and Abu Shara Shamsur. (2008) In vitro Release Kinetic Study of Esomeprazole Magnesium from Methocel K15M and Methocel K100 LVCR Matrix Tablets AAPS.

Chowdary K.P.R, G.B. (2008) Sundari Design and evaluation of bioadhesivecontrolled release oral tablets of glipizide, IJPS.

Deshmukh VN, Harsulkar AA, Sakarkar. (2009) Formulation and in-vitro evaluation of bioadhesive tablets using hydrophilic gum blends. Int J Pharm Res.; 1(1): 16-22.

Goud A. B, Kumara Swamy S, Praveen Kumar V. (2011) Formulation and evaluation of bioadhesive buccal tablets of simvastatin. JAPS/ vol 1/ Issue 1

Gupta A, Garg S, Khar RK. (1993) Measurement of bioadhesive strength of mucoadhesive buccal tablets: Design of an in vitro assembly. Indian Drugs.; 30:152-155.

Harry.G.Brittain (2006) Analytical profiles of Drug substances and Excipients, Volume 23, 53-58.

Kumar P.S, B.Srikanth, T.Satyanarayana, G.Shaji, S.Navaneetha Krishnan, P.Saranya. (2011) Formulation and evaluation of nebivolol mucoadhesive buccal tablet pharmacologyonline.; (3): 869-885.

Matthews B. R. (1999) Regulatory aspects of stability testing in Europe. Drug dev Ind Pharm.; 25(7): 831-856. [DOI] PMid:10459489

Ramana M.V., C Nagda, M Himaja (2007) Design and evaluation of bioadhesivebuccal drug delivery systems containing metoprolol tartrate, IJPS.

Vinod KR, Rohit Reddy T, Sandhya S, David Banji, Venkatram Reddy B. (2012) Critical Review on Mucoadhesive Drug Delivery Systems. Hygeia.J.D.Med.; vol.4 (1).

Vyas S.P, and R.P Khar. (2002) Controlled drug delivery system, Concepts and advances; 1 st edition, 257-295. 